\title{
Machinability of glass fiber reinforced plastic (GFRP) composite materials
}

\author{
Syed Altaf Hussain ${ }^{1 *}$, V. Pandurangadu ${ }^{2}$, K. Palani Kumar ${ }^{3}$ \\ ${ }^{I^{*}}$ Department of Mechanical Engineering, RGM College of Engineering \& Technology, Nandyal-51850, INDIA \\ ${ }^{2}$ Department of Mechanical Engineering, JNTUniveristy-Anantapur, Anantapur-515002, INDIA \\ ${ }^{3}$ Department of Mechanical Engineering, Sri SaiRam Institute of Technology, Chennai-44, INDIA \\ "Corresponding Author: e-mail: s_a_hussain1@rediffmail.com, Tel +91, 9494738100,
}

\begin{abstract}
This paper deals with the study of machinability of GFRP composite tubes of different fiber orientation angle vary from $30^{\circ}$ to $90^{\circ}$. Machining studies were carried out on an all geared lathe using three different cutting tools: namely Carbide (K-20), Cubic Boron Nitride (CBN) and Poly-Crystalline Diamond (PCD). Experiments were conducted based on the established Taguchi's Design of Experiments (DOE) $\mathrm{L}_{25}$ orthogonal array on an all geared lathe. The cutting parameters considered were cutting speed, feed, depth of cut, and work piece (fiber orientation). The performances of the cutting tools were evaluated by measuring surface roughness (Ra) and Cutting force (Fz). A second order mathematical model in terms of cutting parameters was developed using RSM. The results indicate that the developed model is suitable for prediction of surface roughness and Cutting force in machining of GFRP composites.
\end{abstract}

Keywords: GFRP composite materials, Response surface methodology (RSM), ANOVA, Surface roughness, Cutting force.

\section{Introduction}

Glass Fiber Reinforced Plastics (GFRP) Composites are considered to be an alternative to conventional materials. GFRP composites are widely used in variety of applications from aircraft to machine tools due to their light weight, high modulus and specific strength (Hull and Clyne, 1996). Palanikumar et al. (2006) demonstrated that the users of FRP are facing difficulties when machining it, because knowledge and experience acquired for conventional materials cannot be applied for such new materials, whose machinability is different from that of conventional materials. Thus it is desirable to investigate the behavior of FRPs during the machining process. Everstine and Rogers (1971) have proposed an analytical theory of machining FRPs. In a classical study, they developed a theory of plane deformation of incompressible composites reinforced by strong parallel fibers. Sakuma et al (1983) and Bhatnagar et al (1988) studied how the fiber orientation influence both the quality of the machined surfaces and tool wear. The machinability of composite materials is influenced by the type of fiber embedded in the composites, and more particularly by the mechanical properties. On the other hand, Rehman et al (1999) demonstrated that the selection of cutting parameters and the cutting tool are dependent on the type of fiber used in the composites and which is very important in the machining process. Davim and Mata (2004) studied the influence of cutting parameters on surface roughness in turning glass-fiber reinforced plastics using statistical analysis.

Ramulu et al. (1994) carried out a study on machining of polymer composites and concluded that higher cutting speeds give better surface finish. Tekeyama and Lijma (1988) studied the surface roughness on machining of GFRP composites, according to them, higher cutting speed produce more damage on the machined surface. This is attributed to higher cutting temperature, which results in local softening of work material. They also studied the machinability of FRP composites using the ultra sonic machining technique. According to Koing (1985) measurement of surface roughness in FRP is less dependable compared to that in metals, because protruding fiber tips may lead to incorrect results. Additional errors may result from the hooking of the fibers to the stylus. Palanikumar (2008) studied the effect of cutting parameters on surface roughness on machining of GFRP composites by polycrystalline diamond (PCD) tool by developing a second order model for predicting the surface roughness. Palanikumar et al. (2006) have developed a procedure to asses and optimize the chosen factors to attain minimum surface roughness by incorporating response table and response graph, normal probability plot, interaction graphs, and analysis of variance (ANOVA) technique. 
Adamkhan et al. (2011) have carried out machining studies on GFRP composites using two alumina cutting tools. The machining process was performed at different cutting speeds at constant feed rate and depth of cut. The performance of the alumina cutting toll was evaluated by measuring the flank wear and surface roughness of the machined GFRP composite material.

As seen from the literature, only limited work has been carried out on the machinability aspects of Glass fiber Reinforced Plastics (GFRP) composites. Thus, this present work aims at investigating the effects of cutting speed, feed, depth of cut and fiber orientation angle on some aspects of machinability of GFRP composites. In the present investigation, the machinability aspects have been evaluated in terms of surface roughness (Ra) and cutting force (Fz) during the turning of GFRP composites using carbide (K-20), CBN and CBN tools has been analyzed by developing the RSM based second order mathematical model.

The cutting force (Fz) is a function of both cutting speed (v) and feed rate (f), which can be expressed as

Where

$$
\mathrm{Fz}=\Phi(\mathrm{v}, \mathrm{f})
$$

' $\mathrm{v}$ ' is cutting speed, ' $\mathrm{f}$ ' is feed rate and ' $\mathrm{d}$ ' is depth of cut

\section{Materials and Methods}

The work material used for the present investigation is glass fiber reinforced plastics (GFRP) pipes. The inner diameter of the pipe is $30 \mathrm{~mm}$; outer diameter is $60 \mathrm{~mm}$ and length $500 \mathrm{~mm}$ respectively shown in Figure 1. The pipes used in the study are manufactured by filament winding process. The orientation of the fibers on the works piece has been set during the manufacture of pipes. The fiber used in the pipe is E-glass and resign used is epoxy. The specification of the material used in this work is given in Table 1.

Table 1. Specifications of fiber and resign

\begin{tabular}{ll}
\hline \multicolumn{1}{c}{ Fiber: E-glass - R099 1200 P556 } & \multicolumn{1}{c}{ Resin: Epoxy } \\
\hline Manufacturer: Saint Gobain vetrotex India Ltd. & Manufacturer: CIBA GEIGY \\
R099- Multi filament Roving & Product: ARALDITE MY 740 IN \\
1200-Linear Density, Tex & 110KG Q2 \\
P556- Sizing reference for vetrotex & Hardner: HT 972 \\
\hline
\end{tabular}

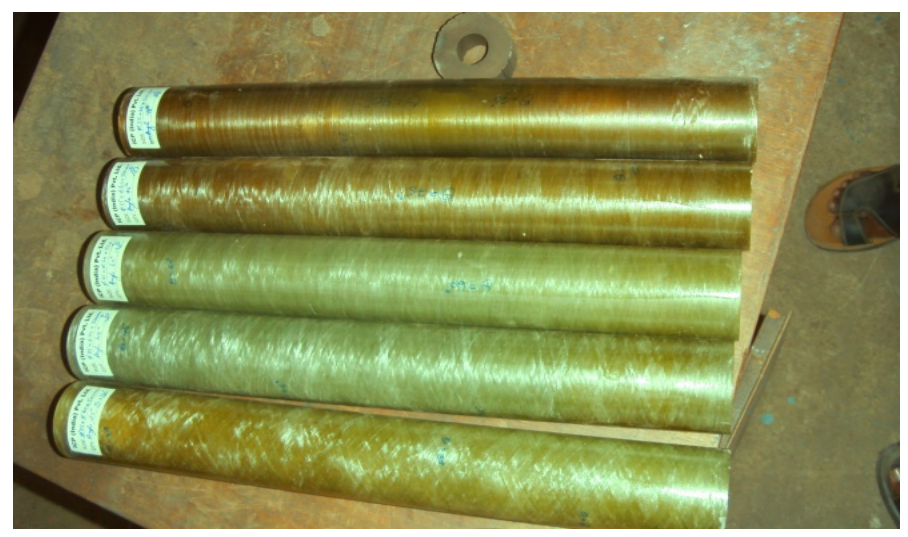

Fig 1. GFRP Composite Pipe Specimens

\subsection{Response Surface Methodology}

The surface finish of machined GFRP composite parts is important in manufacturing engineering applications which have considerable effect on some properties such as wear resistance, light reflection, heat transmission, coating and resisting fatigue. While machining, quality of the part can be achieved through proper cutting conditions. In order to know the surface quality and dimensional properties in advance, it is necessary to employ theoretical models making it feasible to do prediction in function of operation condition. Response surface methodology (RSM) is a collection of mathematical and statistical techniques that are useful for modeling and analysis of problems in which a response of interest is influenced by several variables and the objective is to optimize this response (Montgomery, 1991).

In many engineering fields, there is a relationship between an output variable of interest ' $y$ ' and a set of controllable variables $\left\{\mathrm{x}_{1}, \mathrm{x}_{2} \ldots \ldots \mathrm{x}_{\mathrm{n}}\right\}$. in some systems, the nature of relationship between $\mathrm{y}$ and $\mathrm{x}$ values might be known. Then, a model can be written in the form 


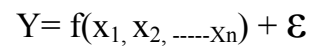

Where $\varepsilon$ represents noise or error observed in the response 'y'

If we denote the expected response be $\mathrm{E}(\mathrm{Y})=\mathrm{f}\left(\mathrm{x}_{1}, \mathrm{x}_{2},---\mathrm{xn}_{\mathrm{n}}\right)=\hat{Y}$ is called response surface. The first step is to find suitable approximation for the true functional relationship between $\mathrm{y}$ and set of independent variables employed usually a second order model is used in RSM.

$$
\widehat{Y}=\beta_{0}+\sum_{i=1}^{k} \beta_{i} X_{i}+\sum_{i=1}^{k} \beta_{i i} X_{i}^{2}+\sum_{i} \sum_{j} \beta_{i j} X_{j}+\varepsilon
$$

The $\beta$ coefficients, used in the above model can be calculated by means of using least square method. The second-order model is normally used when the response function is not known or nonlinear.

\section{Experimental Details}

The experiments are conducted as per the Taguchi's orthogonal array $\mathrm{L}_{25}$ design of experiments. The four cutting parameters selected for the present investigation is cutting speed (v) $\mathrm{m} / \mathrm{min}$, feed (f) $\mathrm{mm} / \mathrm{rev}$, depth of cut (d)mm and work piece (fiber orientation ' $\Phi$ ') in degrees. Since the considered factors are multi-level variables and their outcome effects are not linearly related. The machining parameter used and their levels chosen are given in Table 2. All the GFRP tubes are turned in a BHARAT all-geared lathe of model NAGMATI-175 with a maximum speed of $1200 \mathrm{rpm}$ and power of $2.25 \mathrm{KW}$. The ISO specification of the toll holder used for the turning operation is a WIDAX tool holder PC LNR $2020 \mathrm{~K} 12$ and the tool insert used for the study are carbide K-20, (CNMA 120408), CBN (CNMA 120408T MB825) and PCD (CNMA 120408)

Table 2. Cutting parameters, their notations and their limits

\begin{tabular}{|l|c|c|c|c|c|c|c|}
\hline \multicolumn{2}{|c|}{} & \multicolumn{6}{c|}{ Levels } \\
\hline Process parameters, with units & Notation & Variable & -2 & -1 & 0 & +1 & +2 \\
\hline Cutting speed, m/min & $\mathrm{v}$ & $\mathrm{x}_{1}$ & 40 & 60 & 95 & 145 & 225 \\
\hline Feed, mm/rev & $\mathrm{f}$ & $\mathrm{x}_{2}$ & 0.048 & 0.096 & 0.143 & 0.191 & 0.238 \\
\hline Depth of cut, mm & $\mathrm{d}$ & $\mathrm{x}_{3}$ & 0.25 & 0.5 & 0.75 & 1.0 & 1.25 \\
\hline Fiber orientation angle, degrees & $\Phi$ & $\mathrm{x}_{4}$ & 30 & 45 & 60 & 75 & 90 \\
\hline
\end{tabular}

In machining, the cutting force is measured using a KISTLER quartz 3-component dynamometer type 9257B. The dynamometer measures the active cutting force regardless of its application point. The dynamometer is connected to a 3-channel charge amplifier type 5807A through a connecting cable type 1687B5, this in turn is connected to the PC by a 37-pin cable from the A/D board. The dynamometer is calibrated for the cutting force in the range from 0 to $1000 \mathrm{~N}$. To get accuracy in measuring the cutting force, it is measured three times and average of cutting forces has been taken for analysis. The average surface roughness (Ra), which is mostly used in industrial environments, is taken-up for this study. In a composite machined surface, according to Koing (1985) the result of the roughness depends mainly on the stylus path with respect to fiber direction since the main direction of fibers may change from layer to layer. The absolute value of the roughness profile height over the evaluation length and is denoted by the following equation..

For this reason, the roughness has been measured several times and averaged. The average surface roughness is the integral of

$$
R_{a}=\frac{1}{L} \int_{0}^{L}|Y(x)| d x
$$

Where $\mathrm{L}$ is the length taken for observation, and $\mathrm{Y}$ is the ordinate of the profile curve. The surface roughness was measured by using surface roughness tester (FORM TALY SURF).

\subsection{Mathematical models for $\mathrm{Ra}$, and $\mathrm{Fz}$,}

In the present study, the second-order quadratic RSM based mathematical models were developed for surface roughness (Ra), Cutting force (Fz), are presented in Tables 3-5 for Carbide (K-20) and CBN tool and PCD tool inserts. 
Table 3. Model summary for Carbide (K-20) tool insert

\begin{tabular}{|l|l|}
\hline \multicolumn{1}{|c|}{ Measure of performance } & \multicolumn{1}{|c|}{ Model expression } \\
\hline Surface roughness $(\mathrm{Ra}), \mu \mathrm{m}$ & $2.34-0.0150 \mathrm{v}+7.60 \mathrm{f}-1.47 \mathrm{~d}+0.0497 \Phi+0.000066 \mathrm{v}^{*} \mathrm{v}-8.7 \mathrm{f}^{*} \mathrm{f}$ \\
& $\begin{array}{l}+1.36 \mathrm{~d}^{*} \mathrm{~d}-0.000046 \Phi^{*} \Phi-0.0079 \mathrm{v}^{*} \mathrm{f}+0.00233 \mathrm{v}^{*} \mathrm{~d}-0.000127 \\
\mathrm{~V}^{*} \Phi+1.31 \mathrm{f}^{*} \mathrm{~d}-0.0120 \mathrm{f}^{*} \Phi-0.0238 \mathrm{~d}^{*} \Phi .\end{array}$ \\
\hline Cutting force $(\mathrm{Fz}), \mathrm{N}$ & $294+0.606 \mathrm{v}+950 \mathrm{f}+4 \mathrm{~d}+0.01 \Phi-0.00217 \mathrm{v}^{*} \mathrm{v}-1636 \mathrm{f}^{*} \mathrm{f}-167$ \\
& $\mathrm{~d}^{*} \mathrm{~d}-0.0208 \Phi^{*} \Phi-4.31 \mathrm{v}^{*} \mathrm{f}-0.710 \mathrm{v}^{*} \mathrm{~d}+0.0129 \mathrm{~V}^{*} \Phi+1026 \mathrm{f}^{*} \mathrm{~d}$ \\
& $-3.05 \mathrm{f}^{*} \Phi+3.43 \mathrm{~d}^{*} \Phi$. \\
\hline
\end{tabular}

Table 4. Model summary for CBN tool insert

\begin{tabular}{|l|l|}
\hline \multicolumn{1}{|c|}{ Measure of performance } & Model expression \\
\hline \multirow{3}{*}{ Surface roughness (Ra), $\mu \mathrm{m}$} & $2.91-0.0198 \mathrm{v}+2.86 \mathrm{f}-0.742 \mathrm{~d}+0.0367 \Phi+0.000078 \mathrm{v}^{*} \mathrm{v}+2.4$ \\
& $\mathrm{f}^{*} \mathrm{f}+1.60 \mathrm{~d}^{*} \mathrm{~d}+0.000047 \Phi^{*} \Phi+0.0134 \mathrm{v}^{*} \mathrm{f}+0.00038 \mathrm{v}^{*} \mathrm{~d}-$ \\
& $0.000130 \mathrm{~V}^{*} \Phi-2.73 \mathrm{f}^{*} \mathrm{~d}+0.0144 \mathrm{f}^{*} \Phi-0.0274 \mathrm{~d}^{*} \Phi$. \\
\hline \multirow{3}{*}{ Cutting force (Fz), N } & $293+0.173 \mathrm{v}+502 \mathrm{f}+27 \mathrm{~d}+0.43 \Phi-0.00043 \mathrm{v}^{*} \mathrm{v}-1467 \mathrm{f}^{*} \mathrm{f}-$ \\
& $228 \mathrm{~d}^{*} \mathrm{~d}-0.0187 \Phi^{*} \Phi-6.79 \mathrm{v} * \mathrm{f}+0.233 \mathrm{v}^{*} \mathrm{~d}+0.00988 \mathrm{~V}^{*} \Phi+$ \\
& $1436 \mathrm{f}^{*} \mathrm{~d}+4.46 \mathrm{f}^{*} \Phi+1.53 \mathrm{~d}^{*} \Phi$. \\
\hline
\end{tabular}

Table 5. Model summary for PCD tool insert

\begin{tabular}{|l|l|}
\hline \multicolumn{1}{|c|}{ Measure of performance } & \multicolumn{1}{|c|}{ Model expression } \\
\hline \multirow{3}{*}{ Surface roughness (Ra), $\mu \mathrm{m}$} & $1.19-0.0111 \mathrm{v}+1.84 \mathrm{f}-1.64 \mathrm{~d}+0.0552 \Phi+0.000059 \mathrm{v}^{*} \mathrm{v}-2.93$ \\
& $\begin{array}{l}* \mathrm{f}+1.36 \mathrm{~d}^{*} \mathrm{~d}+0.000055 \Phi^{*} \Phi-0.0122 \mathrm{v}^{*} \mathrm{f}+0.00723 \mathrm{v}^{*} \mathrm{~d}- \\
0.000206 \mathrm{~V}^{*} \Phi+4.05 \mathrm{f}^{*} \mathrm{~d}+0.0141 \mathrm{f}^{*} \Phi-0.0381 \mathrm{~d}^{*} \Phi .\end{array}$ \\
\hline \multirow{3}{*}{ Cutting force (Fz), N } & $293+0.173 \mathrm{v}+502 \mathrm{f}+27 \mathrm{~d}+0.43 \Phi-0.00043 \mathrm{v}^{*} \mathrm{v}-1467 \mathrm{f}^{*} \mathrm{f}-$ \\
& $228 \mathrm{~d}^{*} \mathrm{~d}-0.0187 \Phi^{*} \Phi-6.79 \mathrm{v}^{*} \mathrm{f}+0.233 \mathrm{v}^{*} \mathrm{~d}+0.00988 \mathrm{~V}^{*} \Phi+$ \\
& $1436 \mathrm{f}^{*} \mathrm{~d}+4.46 \mathrm{f}^{*} \Phi+1.53 \mathrm{~d}^{*} \Phi$. \\
\hline
\end{tabular}

Where $\mathrm{v}$ is cutting speed $(\mathrm{m} / \mathrm{min}), \mathrm{f}$ is feed $(\mathrm{mm} / \mathrm{rev}), \mathrm{d}$ is depth of cut $(\mathrm{mm})$ and $\Phi$ is fiber orientation angle in deg.

The statistical testing of the developed mathematical models was done by Fisher's statistical test for the analysis of variance (ANOVA). As per ANOVA, if the calculated value of F-ratio of the regression model is more than the standard tabulated value of the F-table for a given confidence interval, then the model is adequate within the confidence limit. The results of ANOVA at $95 \%$ confidence interval are presented in Table 6 and it is found that the developed mathematical models are highly significant at $95 \%$ confidence interval as F-ratio of all three models is greater than $2.83\left(F_{\text {-table }}(14,10,0.05)\right)$

The coefficient of determination $\left(\mathrm{R}^{2}\right)$ is also determined to test the goodness-of fit of the mathematical model, which provides a measure of variability in the observed values of response and can be explained by the controlled process parameters and their interactions. The $\mathrm{R}^{2}$ values of the developed models are given in Table 7, which clearly indicate the excellent correlation between the experimental and the predicted values of the responses. Adjusted $\mathrm{R}^{2}$ is a modified $\mathrm{R}^{2}$ that has been adjusted to for the number of terms in the model. In this paper including insignificant terms, $\mathrm{R}^{2}$ can be artificially high. Unlike $\mathrm{R}^{2}$, adjusted $\mathrm{R}^{2}$ may get smaller when added to the model. Because the adjusted $\mathrm{R}^{2}$ takes in to consideration the number of independent variables in the model. When $\mathrm{R}^{2}$ and adjusted $\mathrm{R}^{2}$ differ dramatically, there is a good chance that non-significant terms have been included in the model. From the Table 7 shows that $R^{2}$ and adjusted $R^{2}$ are found to be very close, that indicate that all the terms included in the model are significant. 
Table 6. ANOVA results for surface roughness, cutting force, specific cutting pressure and cutting power models of three different tools viz: Carbide (K-20), CBN and PCD.

\begin{tabular}{|c|c|c|c|c|c|c|c|}
\hline \multirow[b]{2}{*}{ Response } & \multicolumn{2}{|c|}{ Sum of squares } & Degree of & reedom & \multicolumn{2}{|c|}{ Mean square } & \multirow[b]{2}{*}{ F-ratio } \\
\hline & Regression & Residual & Regression & Residual & Regression & Residual & \\
\hline
\end{tabular}

Tool: Carbide (K-20)

Surface roughness: $7.15446 \quad 0.13095$

Cutting force $\quad: 107647.8 \quad 3135.6$

$\underline{\text { Tool : CBN }}$

Surface roughness : 5.92233

Cutting force $\quad: 92439.1$

0.14201

3174.0

14

14

14
14

10

10

0.51103

0.01310

$\begin{array}{lll}7689.1 & 313.6 & 24.52\end{array}$

39.02

Tool: PCD

Surface roughness : $5.62209 \quad 0.08226$

Cutting force $\quad: 125355.9 \quad 3660.1$
14

14
10

10

10

10
0.42302

6602.8
0.01420

317.4
29.79

20.80

Table 7 Coefficient of determination values for surface roughness, cutting force, specific cutting pressure and cutting power models of three different cutting tools viz: Carbide (K-20),CBN and PCD cutting tool inserts.

\begin{tabular}{|l|l|l|l|}
\hline \multirow{2}{*}{ Type of tool } & Response & $\begin{array}{l}\text { Adj } R- \\
\text { square }\end{array}$ & $R^{2}$ \\
\hline \multirow{2}{*}{ Carbide (K-20) } & Surface roughness (Ra) & 0.957 & 0.982 \\
\cline { 2 - 4 } & Cutting force (Fz) & 0.932 & 0.9511 \\
\hline \multirow{2}{*}{ CBN } & Surface roughness (Ra) & 0.93 & 0.9576 \\
\cline { 2 - 4 } & Cutting force (Fz) & 0.92 & 0.9667 \\
\hline \multirow{2}{*}{ PCD } & Surface roughness (Ra) & 0.965 & 0.9526 \\
\cline { 2 - 4 } & Cutting force (Fz) & 0.932 & 0.9716 \\
\hline
\end{tabular}

From the models, it was revealed that the co-efficient of determination $\left(\mathrm{R}^{2}\right)$ is more than $90 \%$ in all the cases, which shows high correlation exists between the model and experimental values.

\section{Results and Discussions}

In the present work a comprehensive analysis is carried out to study the effect of different cutting tool material on various machining characteristics viz., surface roughness, cutting force, specific cutting pressure and cutting power with variation of cutting speed, feed, and depth of cut for different fiber orientation angle GFRP composites. For analyzing the influence of machining parameters on machining of different fiber orientation angle $\left(30^{\circ}-90^{\circ}\right)$ GFRP composites, the machinability aspects, viz: surface roughness, and cutting force are calculated at different machining conditions and are plotted as shown in Figures 5-7 and Figures 11-13. The graphs are drawn with the help of response surface model observed. In these graphs only one variable is in variation in nature by keeping other variables constant at the middle level.

\subsection{Analysis of surface roughness}

Surface roughness plays a predominant role in determining the machining accuracy. The study of surface roughness characteristics of GFRP composites dependent on many factors, it is more influenced by the cutting parameters like cutting speed, feed, depth of cut, etc., for a given machine tool and work piece set-up. The machining of FRP differs in many respects from that of metals. The behavior of composites is heterogeneous and depends on the fiber and matrix properties, orientation of fibers, bond 
strength between fiber and matrix, and the type of weave. It is known that the mechanism of cutting in GFRP composites is due to the combination of plastic deformation, shearing, and bending rupture. The occurrence of above mechanism depends on the flexibility, orientation and toughness of the fibers, these constitute a surface texture on the work piece. The effects of cutting tool material on surface roughness at various machining conditions are shown in Figures 5-7.

Table 8 : Response table for surface roughness for Carbide (K-20) Insert

\begin{tabular}{|c|c|c|c|c|}
\hline Level & $\begin{array}{c}\text { Cutting speed(v) } \\
\mathrm{m} / \mathrm{min}\end{array}$ & $\begin{array}{c}\text { Feed (f) } \\
\mathrm{mm} / \mathrm{min}\end{array}$ & $\begin{array}{l}\text { Depth of } \\
\text { cut(d) } \mathrm{mm}\end{array}$ & $\begin{array}{c}\text { Fiber orientation } \\
\text { angle( }(\Phi) \mathrm{deg}\end{array}$ \\
\hline 1 & 3.847 & 2.876 & 3.625 & 3.109 \\
\hline 2 & 3.731 & 3.203 & 3.540 & 3.301 \\
\hline 3 & 3.403 & 3.569 & 3.368 & 3.487 \\
\hline 4 & 3.041 & 3.758 & 3.254 & 3.612 \\
\hline 5 & 3.198 & 3.815 & 3.434 & 3.711 \\
\hline Delta & 0.806 & 0.939 & 0.371 & 0.602 \\
\hline Rank & 2 & 1 & 4 & 3 \\
\hline
\end{tabular}

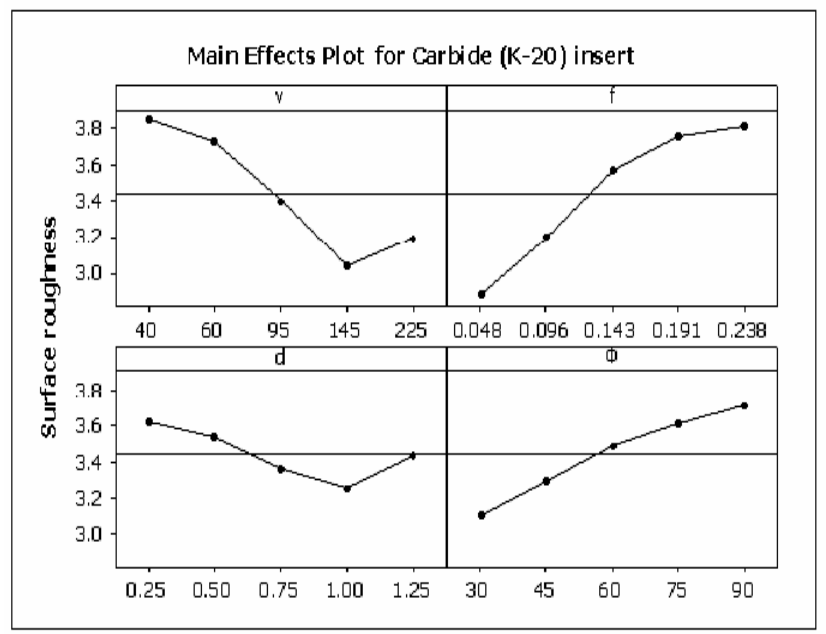

Table 9 : Response table for surface roughness for CBN

Figure 2: Effect plot of surface roughness for Carbide insert (K-20) insert

\begin{tabular}{|c|c|c|c|c|}
\hline Level & $\begin{array}{c}\text { Cutting speed(v) } \\
\mathrm{m} / \mathrm{min}\end{array}$ & $\begin{array}{c}\text { Feed (f) } \\
\mathrm{mm} / \mathrm{min}\end{array}$ & $\begin{array}{c}\text { Depth of } \\
\text { cut(d) } \mathrm{mm}\end{array}$ & $\begin{array}{c}\text { Fiber orientation } \\
\text { angle }(\Phi) \text { deg }\end{array}$ \\
\hline 1 & 3.744 & 2.842 & 3.515 & 3.101 \\
\hline 2 & 3.683 & 3.201 & 3.529 & 3.292 \\
\hline 3 & 3.323 & 3.452 & 3.249 & 3.373 \\
\hline 4 & 2.995 & 3.659 & 3.243 & 3.503 \\
\hline 5 & 3.132 & 3.722 & 3.340 & 3.607 \\
\hline Delta & 0.749 & 0.879 & 0.287 & 0.506 \\
\hline Rank & 2 & 1 & 4 & 3 \\
\hline
\end{tabular}

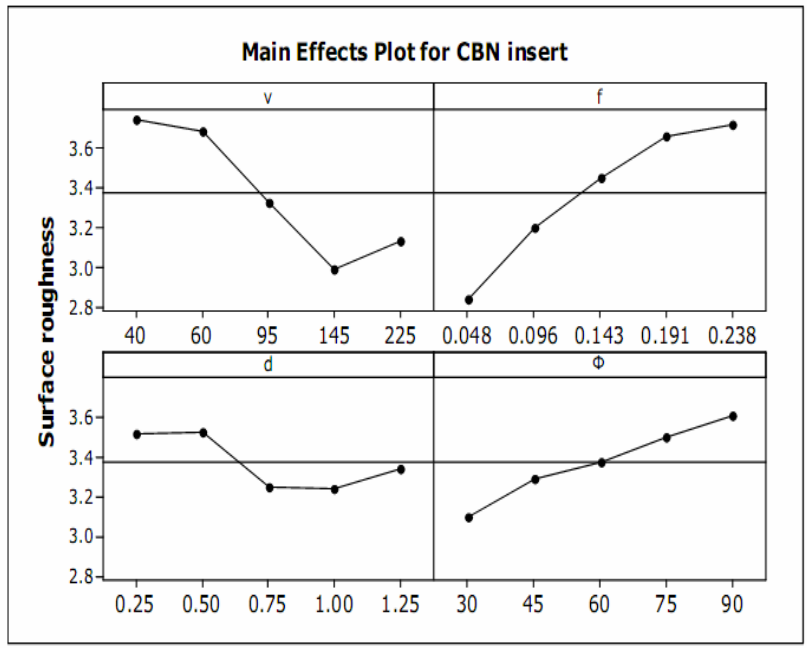

Figure 3: Effect plot of surface roughness for CBN insert

Surface roughness plays a predominent role in determining the machining accuracy. The study of surface roughness characteristics of GFRP composites dependent on many factors, it is more influenced by the cutting parameters like cutting speed, feed, depth of cut etc., for a given machine tool and work piece set-up. The influnce of different cutting parameters on machining of GFRP composites can be studied by using response graph and response table. Tables 8-10 show the effect of different cutting parameters. From the response tables, it can be asserted that feed is the main parameter which affect the surface roughness followed by cutting speed, fiber orientation and and depth of cut. Figures 2-4 show the influence of cutting parameters on surface roughness for three different cutting tools namely carbide (K-20), CBN and PCD. The observed surface roughness at high cutting speed is low as compared to low cutting speed. The experimental results indicated that the surface roughness is low at low feed as compared to the high feed. The effect of depth of cut on machining of GFRP composite indicated that the surface roughness reduces with increase of depth of cut. The experimental results indicated that low surface roughness is observed for low fiber orientation angle as compared to high fiber orientation angle. 
Table 10: Response table for surface roughness for PCD insert

\begin{tabular}{|c|c|c|c|c|}
\hline Level & $\begin{array}{c}\text { Cutting speed(v) } \\
\mathrm{m} / \mathrm{min}\end{array}$ & $\begin{array}{c}\text { Feed (f) } \\
\mathrm{mm} / \mathrm{min}\end{array}$ & $\begin{array}{l}\text { Depth of } \\
\text { cut(d) } \mathrm{mm}\end{array}$ & $\begin{array}{c}\text { Fiber orientation } \\
\text { angle( }(\Phi) \text { deg }\end{array}$ \\
\hline 1 & 2.582 & 1.796 & 2.377 & 1.904 \\
\hline 2 & 2.474 & 1.989 & 2.340 & 2.033 \\
\hline 3 & 2.206 & 2.371 & 2.181 & 2.327 \\
\hline 5 & 1.922 & 2.460 & 2.123 & 2.382 \\
\hline 5 & 1.997 & 2.566 & 2.161 & 2.536 \\
\hline Delta & 0.661 & 0.770 & 0.254 & 0.631 \\
\hline Rank & 2 & 1 & 4 & 3 \\
\hline
\end{tabular}

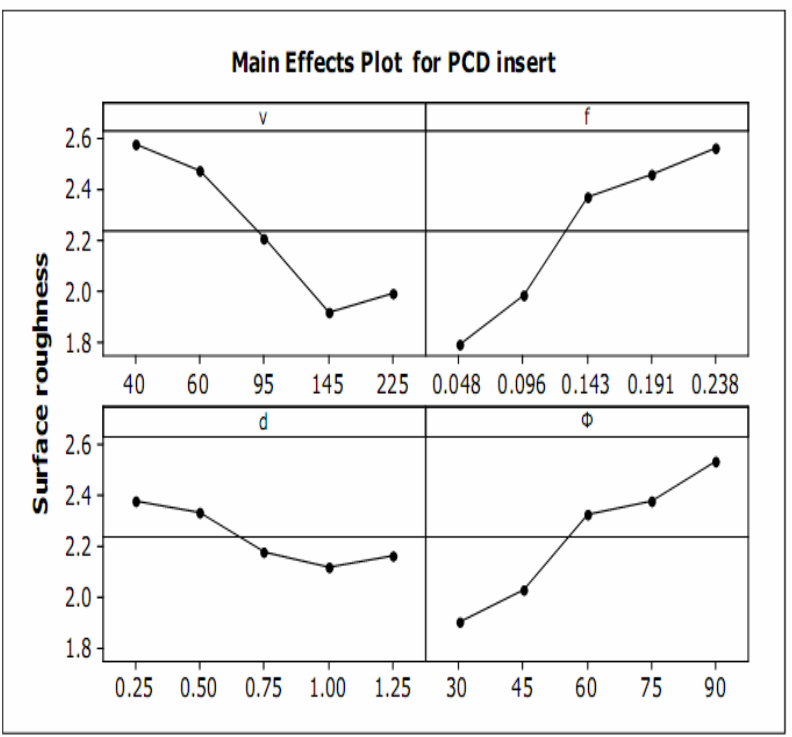

Figure 4: Effect plot of surface roughness for PCD insert

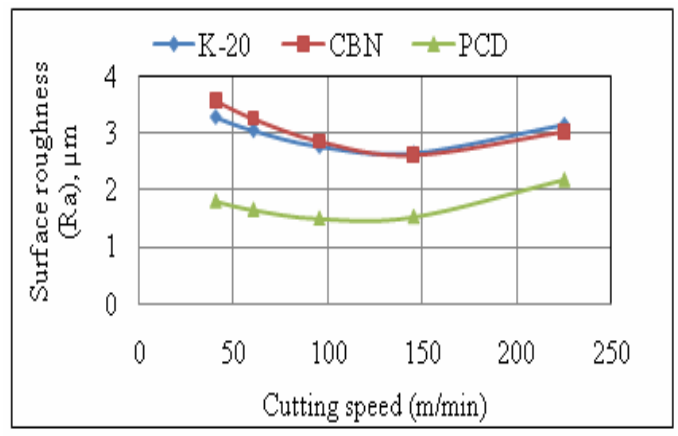

(a) Effect of cutting tool material on surface roughness with varying cutting speed for $30^{\circ}$ Fiber orientation angle GFRP composite.

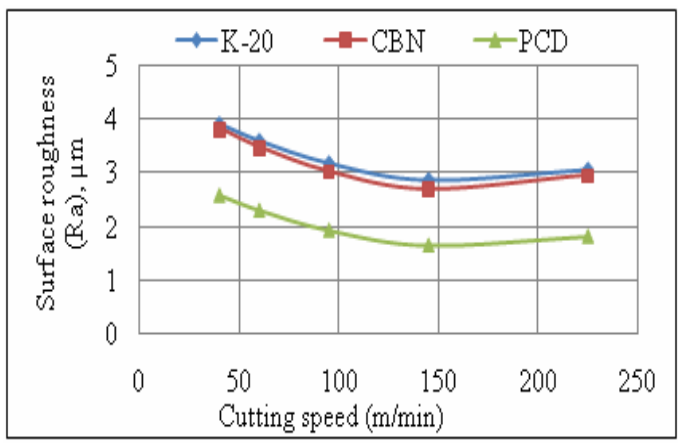

(c) Effect of cutting tool material on surface roughness with varying cutting speed for $60^{\circ}$ Fiber orientation angle GFRP composite.

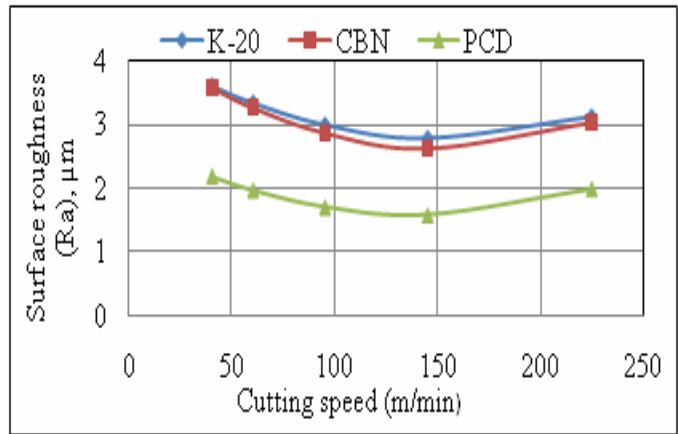

(b) Effect of cutting tool material on surface roughness with varying cutting speed for $45^{\circ}$ fiber orientation GFRP composite.

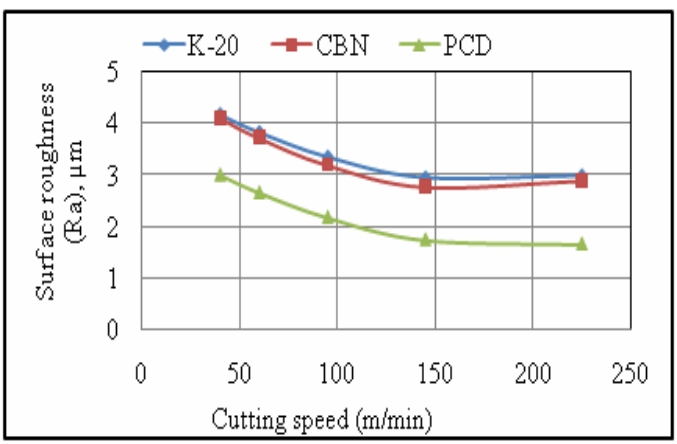

(d) Effect of cutting tool material on surface roughness with varying cutting speed for $75^{\circ}$ fiber orientation GFRP composite

Figure 5 (a-d) Effect of cutting tool materials with varying cutting speed on surface roughness of GFRP composites 


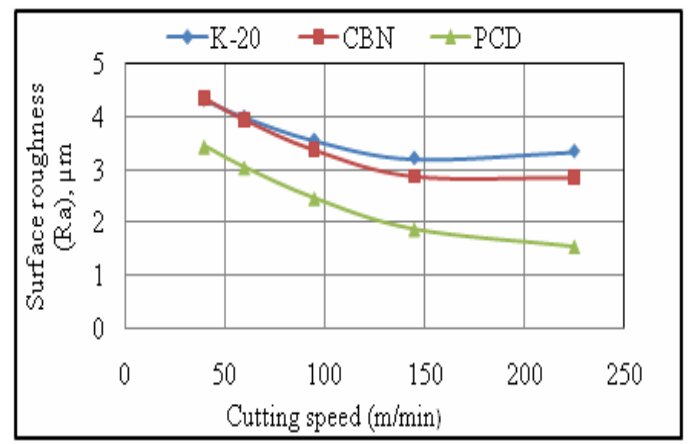

(e) Effect of cutting tool material on surface roughness With varying cutting speed for $90^{\circ}$ fiber orientation angle GFRP composite.

Figure 5 (e) cont'd. Effect of cutting tool materials with varying cutting speed on surface roughness of GFRP composites

The factor affecting the surface roughness in machining of GFRP composites is the cutting speed, for analyzing the influence of machining parameters in machining of GFRP composites, the surface roughness values are calculated at different machining conditions for different fiber orientation angle GFRP composites and are plotted as shown in Figure 5 (a-e). The graphs are drawn with the help of response surface model observed. In these graphs only one variable is in variation in nature by keeping other variables constant at the middle level. Figure 5 (a-e) clearly represents the variation of surface roughness with the cutting speed at constant values of feed, depth of cut and fiber orientation angle. It can be observed that the surface roughness gradually decreases for the three different cutting tool inserts with increasing the cutting speed up to $145 \mathrm{~m} / \mathrm{min}$ and thereafter it increases slightly. This is because, at higher cutting speed debonding and fiber breakage are the reasons for poor surface roughness. During machining of GFRP composites, at lower cutting speed large material flow with the cut fibers has been noticed which intern produce high surface roughness. It can be noted that the surface roughness of the machined GFRP composite material range from 1.51 to $3.1542 \mu \mathrm{m}$ (microns) for $30^{\circ}$ fiber orientation angle GFRP composite material. Fiber orientation angle plays an important role for deciding the surface roughness. It is noted from the graphs that, higher values of surface roughness are observed for higher fiber orientation angle GFRP composite materials. These results are in close agreement with the results of palanikumar et al (2004).

From the above figures, it can be asserted that moderate cutting speed is preferred for machining GFRP composite materials of different fiber orientation angle. The above figure also reveals that Poly-Crystalline Diamond cutting (PCD) tool produced better surface finish among the other cutting tools used for the study. This is followed by Cubic Boron Nitride (CBN) tool.

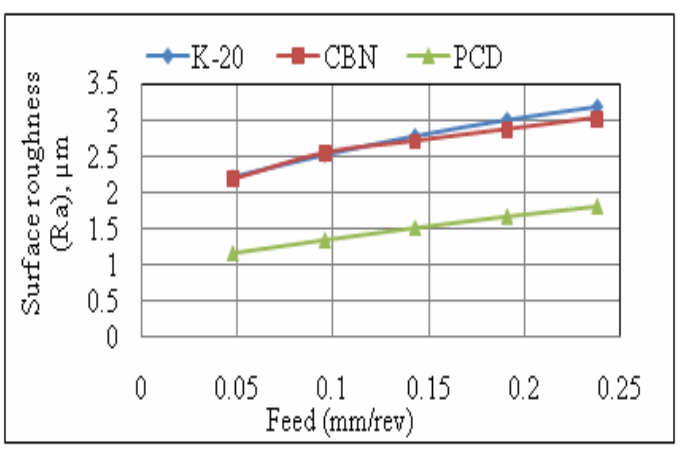

(a) Effect of cutting tool material on surface roughness with varying feed for $30^{\circ}$ fiber orientation angle GFRP compoiste.

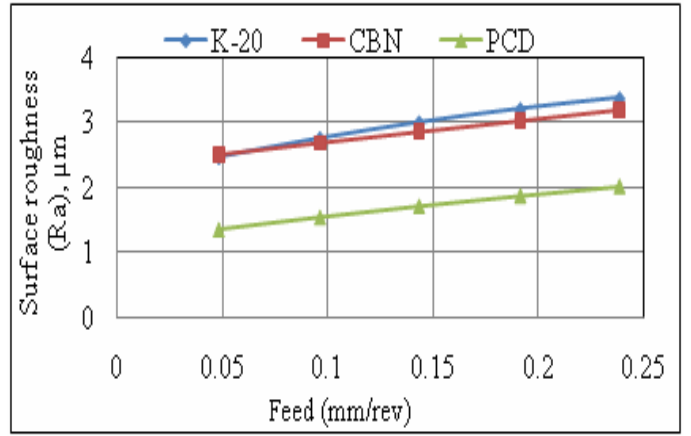

(b) Effect of cutting tool material on surface roughness with varying feed for $45^{\circ}$ fiber orientation angle GFRP composite.

Figure 6 (a-b) Effect of cutting tool materials with varying feed on surface roughness of GFRP composites. 


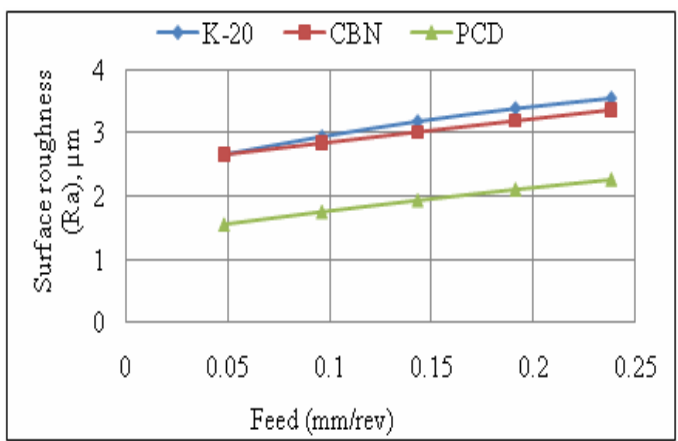

(c) Effect of cutting tool material on surface roughness with varying feed for $60^{\circ}$ fiber orientation angle GFRP compoiste.

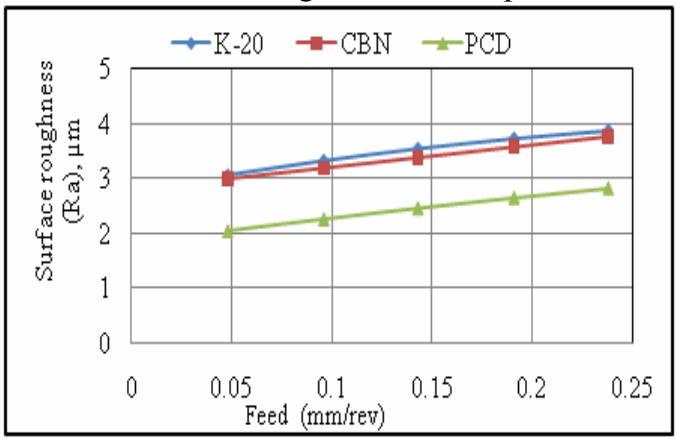

(e) Effect of cutting tool material with on surface roughness

with varying feed for $90^{\circ}$ fiber orientation angle GFRP composite

Figure 6 (c-e) cont'd. Effect of cutting tool materials with varying feed on surface roughness of GFRP composites.

Figure 6(a-e), shows the graphs plotted between feed and surface roughness at constant cutting speed, depth of cut and fiber orientation angle. From the graphs it is asserted that a steady increase in surface roughness is observed with the increase in feed for the range of fiber orientation angle $\left(30^{\circ}\right.$ to $\left.90^{\circ}\right)$ GFRP composite materials with the three different cutting tool inserts used in this study. The results are in close agreement with the results stated by sarma et al (2009). The increase in the feed rate increases the heat generation and hence, tool wear, which resulted in the higher surface roughness. The increase in the feed rate also increases the chatter and it produces incomplete machining at faster traverse, which leads to higher surface roughness. It is noted that, lower values of surface roughness ranges from $1.1713-1.7939 \mu \mathrm{m}$ (microns) for $30^{\circ}$ fiber orientation angle GFRP composite material with PCD cutting tool insert. The surface roughness is more for $90^{\circ}$ orientation angle GFRP composite materials for all the range of feed rates for the three different cutting tools used in this study. This finding has close relationship with results presented by Takeyama and LiJima (1988). From the above figures, it is asserted that low feed rates and low fiber orientation angle are preferred for machining GFRP composite materials. The above figure also reveals that Poly-Crystalline Diamond cutting (PCD) tool produced better surface finish among the other cutting tools used for the study. This is followed by Cubic Boron Nitride (CBN) tool.

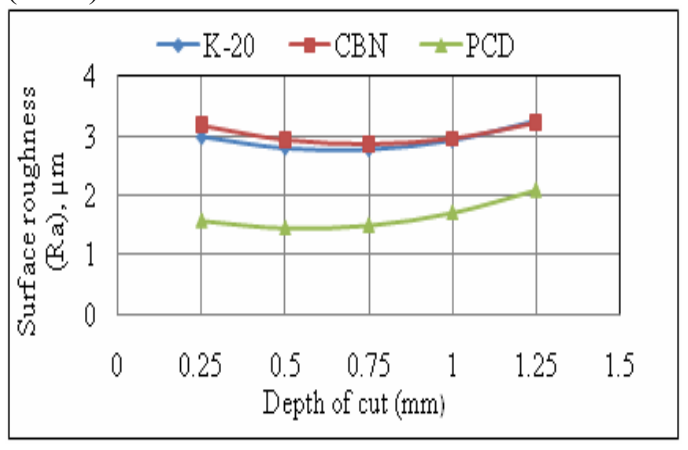

(a) Effect of cutting tool material on surface roughness roughness with varying depth of cut for $30^{\circ}$ fiber orientation angle GFRP composite. Figure 7 (a-b) Effect of cutting tool materials with varying depth of cut on surface roughness of GFRP composites.

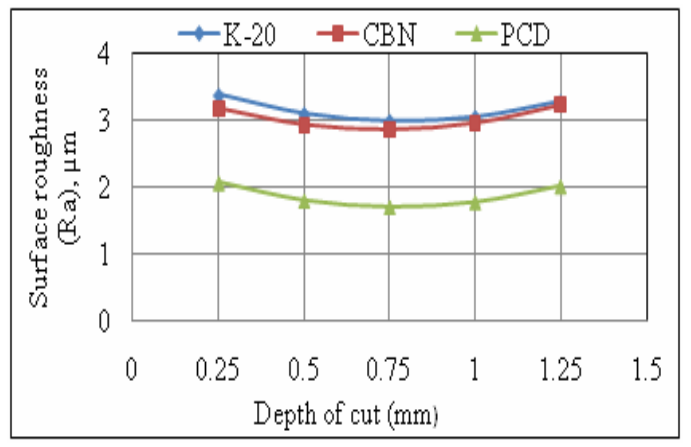

(b) Effect of cutting tool material on surface roughness with varying depth of cut for $45^{0}$ fiber orientation angle GFRP composite. d) Effect of cutting tool material on surface roughness with varying feed for $75^{\circ}$ fiber orientation angle GFRPcomposite 


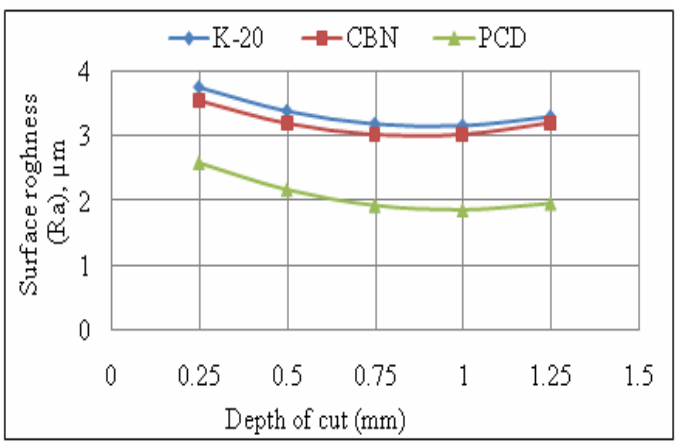

(c) Effect of cutting tool material on surface roughness roughness with varying depth of cut for $60^{\circ}$ fiber orientation angle GFRP composite.

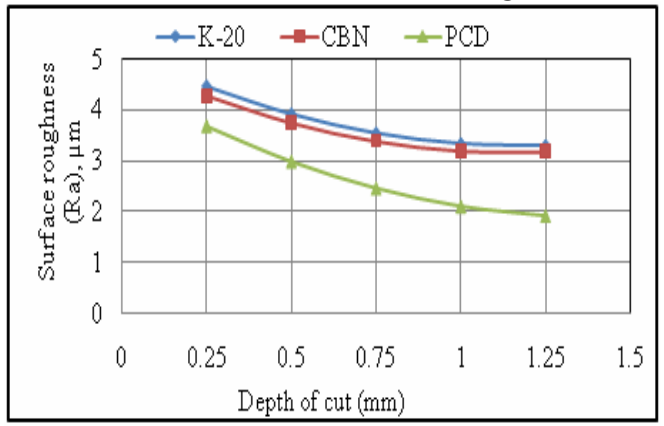

(e) Effect of cutting tool material on surface roughness with varying depth of cut for $90^{\circ}$ fiber orientation angle GFRP composite

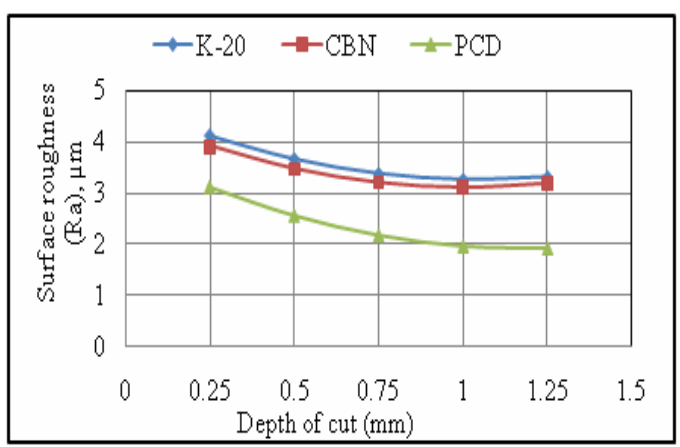

(d) Effect of cutting tool material on surface roughness with varying depth of cut for $75^{\circ}$ fiber orientation angle GFRP composite.

Figure 7 (c-e) cont'd. Effect of cutting tool materials with varying depth of cut on surface roughness of GFRP composites.

Figure 7(a-e), shows the graphs plotted between surface roughness with varying depth of cut at constant cutting speed, feed and fiber orientation angle for GFRP composite materials whose fiber orientation angle vary from $\left(30^{\circ}\right.$ to $\left.90^{\circ}\right)$. From the graphs it is asserted that a gradual decrease in surface roughness is observed with the increase in depth of cut up to $0.75 \mathrm{~mm}$ to $1.0 \mathrm{~mm}$ thereafter slightly increases for the range of fiber orientation angle $\left(30^{\circ}\right.$ to $\left.90^{\circ}\right)$ GFRP composite materials with the three different cutting tool inserts used in this study. According to Sang.-Ook An et al (1997) depth of cut plays a small role in composite machining process compared to cutting speed and feed rate, but the higher depth of cut causes a deleterious effect on surface quality in GFRP machining and hence moderate depth of cut are preferred for machining GFRP composite materials. It can be seen from the graphs that, lower surface roughness values are observed with in range from $1.4658 \mu \mathrm{m}$ to $2.1131 \mu \mathrm{m}$ on $30^{\circ}$ fiber orientation angle GFRP composite material with PCD cutting tool insert, and at larger fiber orientation angle it increases steeply, this is due to the fact that larger fiber orientation angle, a larger compressive strain generated with in the work material.

From the above figures, it is asserted that moderate depth of cut and low fiber orientation angle are preferred for machining GFRP composite materials. The above figure also reveals that Poly-Crystalline Diamond cutting (PCD) tool produced better surface finish among the other cutting tools used for the study. This is followed by Cubic Boron Nitride (CBN) tool. Carbide (k20) was not satisfactory compared to the other tools used in this investigation. PCD cutting tools are designed to machine tough, abrasive non ferrous and non-metallic materials, they are very hard and maintain a keen cutting edge for long production runs. The sharp cutting edge shear the chip clearly and reduce the friction force of the chip sliding over rake surface of the tool by virtue of this closer dimensional tolerance is obtained on GFRP composites.

\subsection{Analysis of cutting force}

The cutting force in the machining process is produced due to the sliding of the cutting tool against the work piece in order to remove the material from the work piece. The cutting tool geometry, tool materials, and machining conditions are responsible for higher cutting forces which in turn produce worse surface texture. The presences of glass fiber with brittle behavior of the reinforcement reduce the contact area and promote low cutting force. The main mechanisms represent the cutting force in machining FRP composite, namely shearing in the perpendicular direction and buckling in the parallel direction. The effect of cutting tool material on cutting force at various machining conditions in machining of GFRP composites are shown in Figures 1113 . 
The study of cutting force characteristics of GFRP composites dependent on many factors, it is more influenced by the cutting parameters like cutting speed, feed, depth of cut, etc., for a given machine tool and work piece set-up. The influence of different cutting parameters on machining of GFRP composites can be studied by using response graph and response table. The influence of different cutting parameters on machining of GFRP composites can be studied by using response graph and response table. Tables 11-13 show the response table for Cutting force on machining GFRP composite using carbide (K-20) tool insert, CBN tool insert and PCD tool insert. From the response table, it can be asserted that feed is the main parameters which affect the cutting force, followed by cutting speed and fiber orientation angle. Figures 8-10 show the influence of different cutting parameters on cutting force. The observed cutting force is high at low cutting speed as compared to high cutting speed. The experimental results indicated that that the cuttings force is low at low feed as compared to high feed. Cutting force is greatly influenced by the fiber orientation angle. When the orientation angle differs, the distance between the fibers may vary and accordingly, the cutting force increases. The effect of depth of cut in machining of GFRP composites by three different cutting tools inserts viz., Carbide (K-20), $\mathrm{CBN}$ and $\mathrm{PCD}$ is minimal when compared to other machining parameters.

Table 11 : Response table for cutting force (Fz) for Carbide(K-20) tool

\begin{tabular}{|c|c|c|c|c|}
\hline Level & $\begin{array}{c}\text { Cutting speed(v) } \\
\mathrm{m} / \mathrm{min}\end{array}$ & $\begin{array}{c}\text { Feed (f) } \\
\mathrm{mm} / \mathrm{min}\end{array}$ & $\begin{array}{c}\text { Depth of } \\
\text { cut(d) } \mathrm{mm}\end{array}$ & $\begin{array}{c}\text { Fiber orientation } \\
\text { angle( }(\mathrm{d}) \text { deg }\end{array}$ \\
\hline 1 & 53.56 & 51.13 & 52.16 & 51.68 \\
\hline 2 & 52.81 & 52.00 & 52.34 & 51.84 \\
\hline 3 & 52.23 & 52.55 & 52.52 & 52.13 \\
\hline 4 & 51.87 & 52.87 & 52.33 & 52.74 \\
\hline 5 & 51.47 & 53.38 & 52.60 & 53.54 \\
\hline Delta & 2.09 & 2.25 & 0.44 & 1.86 \\
\hline Rank & 2 & 1 & 4 & 3 \\
\hline
\end{tabular}

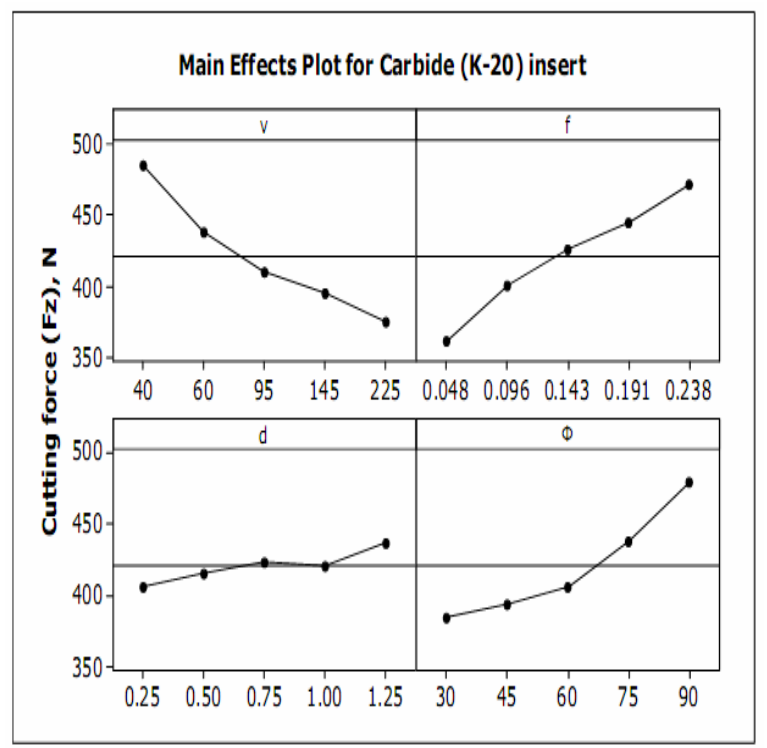

Figure 8: Effect plot for cutting force (Fz) for carbide (K-20) tool.

Table 12 : Response table for cutting force (Fz) for CBN tool

\begin{tabular}{|c|c|c|c|c|}
\hline Level & $\begin{array}{c}\text { Cuuting speed(v) } \\
\text { m/min }\end{array}$ & $\begin{array}{c}\text { Feed (f) } \\
\text { mm min }\end{array}$ & $\begin{array}{l}\text { Depth of } \\
\text { cut(d) mm }\end{array}$ & $\begin{array}{c}\text { Fiber orientation } \\
\text { angle( }(\Phi) \text { deg }\end{array}$ \\
\hline 1 & 456.9 & 343.2 & 380.6 & 356.4 \\
\hline 2 & 390.7 & 360.2 & 391.1 & 365.9 \\
\hline 4 & 378.5 & 387.1 & 386.4 & 383.7 \\
\hline 5 & 371.9 & 446.8 & 393.3 & 440.2 \\
\hline Delta & 90.8 & 103.6 & 27.1 & 83.7 \\
\hline Rank & 2 & 1 & 4 & 3 \\
\hline
\end{tabular}

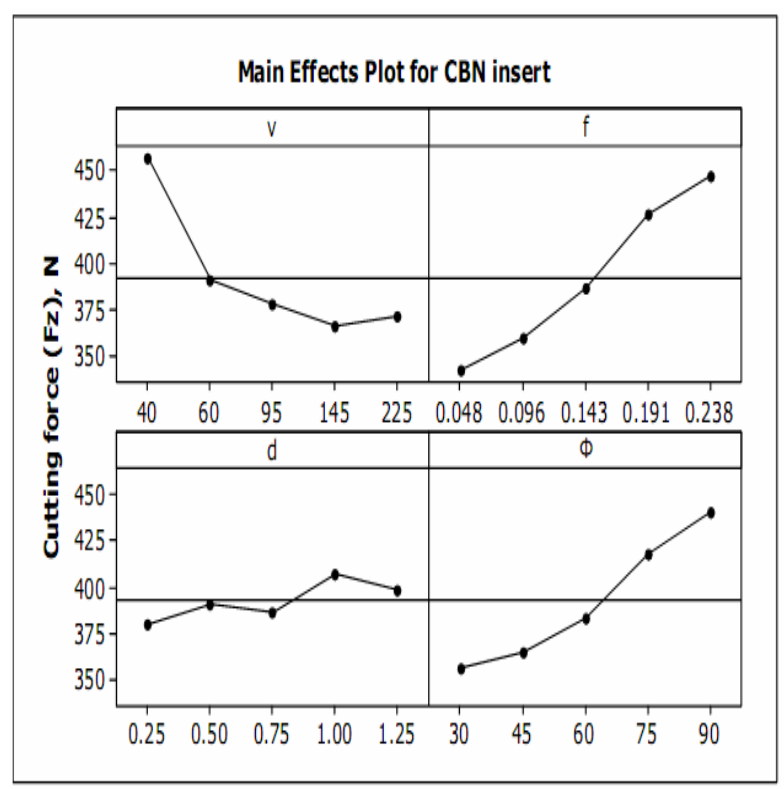


Figure 9: Effect plot for cutting force (Fz) for CBN tool

Table 13: Response table for cutting force (Fz) for PCD tool

\begin{tabular}{|c|c|c|c|c|}
\hline Level & $\begin{array}{c}\text { Cutting speed(v) } \\
\mathrm{m} / \mathrm{min}\end{array}$ & $\begin{array}{l}\text { Feed (f) } \\
\mathrm{mm} / \mathrm{min} \\
\end{array}$ & $\begin{array}{l}\text { Depth of } \\
\text { cut(d) mmm }\end{array}$ & $\begin{array}{c}\text { Fiber orientation } \\
\text { angle( }(\Phi) \text { deg }\end{array}$ \\
\hline 1 & 387.7 & 257.5 & 296.9 & 262.4 \\
\hline 2 & 345.0 & 290.0 & 298.7 & 295.3 \\
\hline 3 & 296.4 & 320.9 & 332.9 & 333.0 \\
\hline 4 & 275.6 & 344.4 & 340.0 & 344.8 \\
\hline 5 & 285.4 & 377.4 & 321.6 & 354.7 \\
\hline Delta & 112.1 & 120.0 & 43.1 & 92.3 \\
\hline Rank & 2 & 1 & 4 & 3 \\
\hline
\end{tabular}

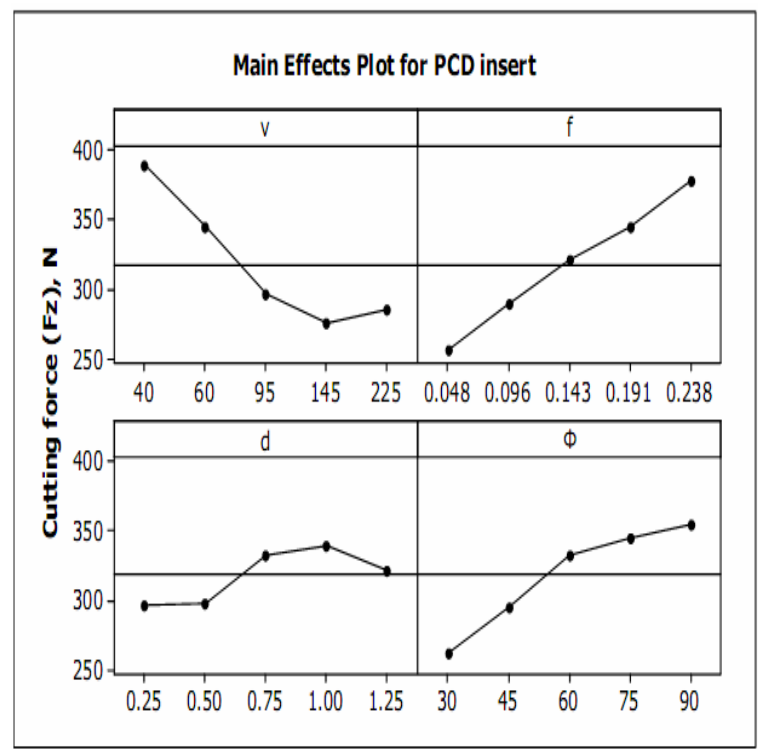

Figure 10 : Effect plot for cutting force (Fz) for PCD tool

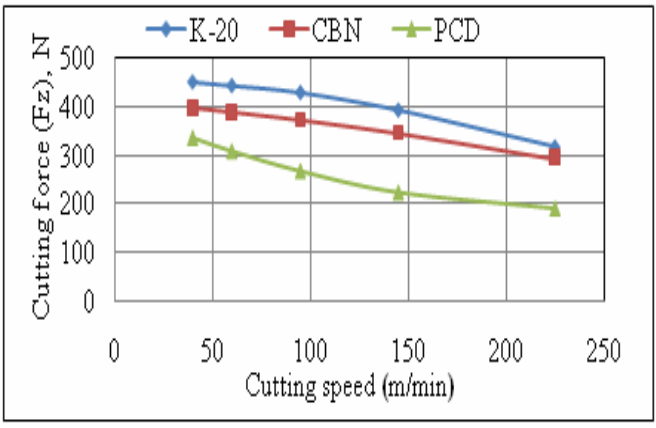

(a) Effect of cutting tool material on cutting force with varying cutting speed for $30^{\circ}$ fiber orientation angle GFRP compoiste.

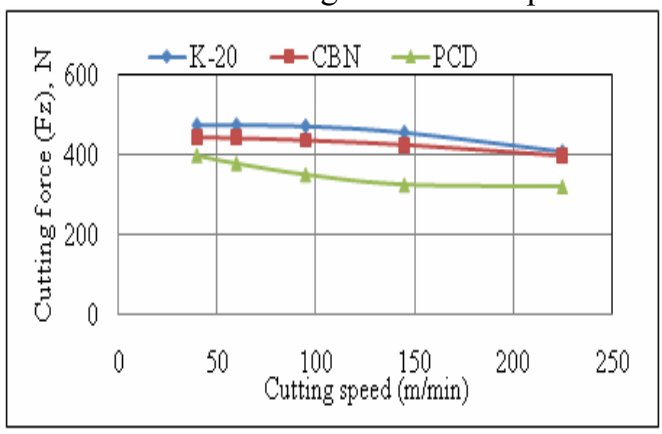

(c) Effect of cutting tool material on cutting force with varying cutting speed for $60^{\circ}$ fiber orientation angle GFRP compoiste.

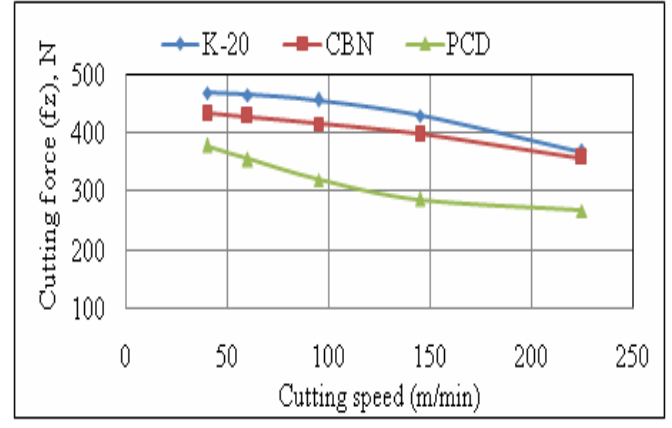

(b) Effect of cutting tool material on cutting force with varying cutting speed for $45^{\circ}$ fiber orientation angle GFRP compoiste.

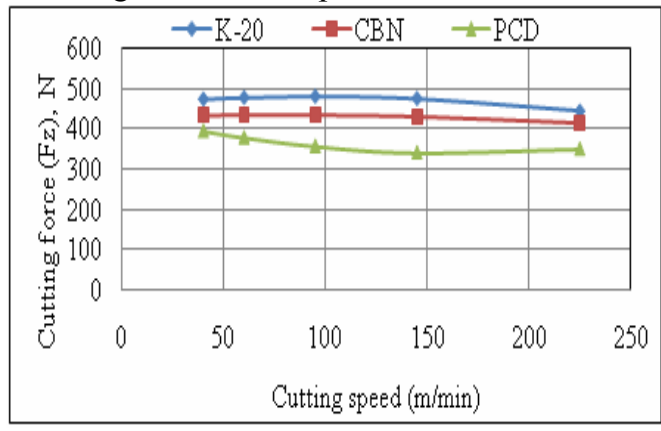

(d) Effect of cutting tool material on cutting force with varying cutting speed for $75^{\circ}$ fiber orientation angle GFRP compoiste.

Figure 11 (a-d) Effect of cutting tool material on cutting force with varying cutting speed 


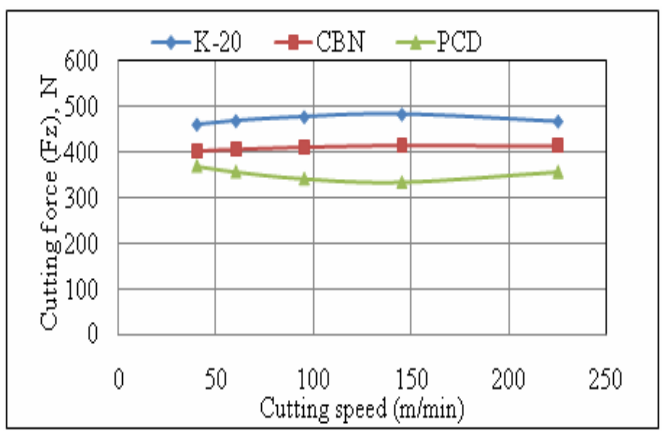

(e) Effect of cutting tool material on cutting force with varying cutting speed for $90^{\circ}$ fiber orientation angle GFRP composite.

Figure 11 (e) cont'd. Effect of cutting tool material on cutting force with varying cutting speed

For analyzing influence of cutting tool material the on cutting force $(\mathrm{Fz})$ in machining of GFRP composite material with varying cutting speed, the cutting forces are calculated for each fiber orientation angle GFRP composite material with the help of response surface model by keeping the one variable in variation in nature by keeping the other variable constant at the middle level. Figure 11 (a-e), shows the effect of cutting tool material on cutting force with varying cutting speed for different fiber orientation angle GFRP composite materials. It can be seen from the graphs that, the cutting force decreases with increase of cutting speed for all the cutting tool inserts used in this study. The decrease in the cutting force is due to the decrease in tool chip contact and increase in and increase in the cutting zone area, leading to the reduction in shear strength of the work piece. The results indicates that, the cutting forces are minimum for $30^{\circ}$ fiber orientation angle GFRP composite material machining with PCD cutting tool insert ranges from $191.73 \mathrm{~N}$ to $334.92 \mathrm{~N}$. Figure11(d-e) indicates that the cutting force increases with increase of fiber orientation angle. This may be due to increase of compressive stresses at larger fiber orientation angle. This finding has close relationship with results presented by Takeyama and LiJima (1988). From the graphs it is asserted that the performance of PCD tool is superior to the other two cutting tool inserts used in this investigation.

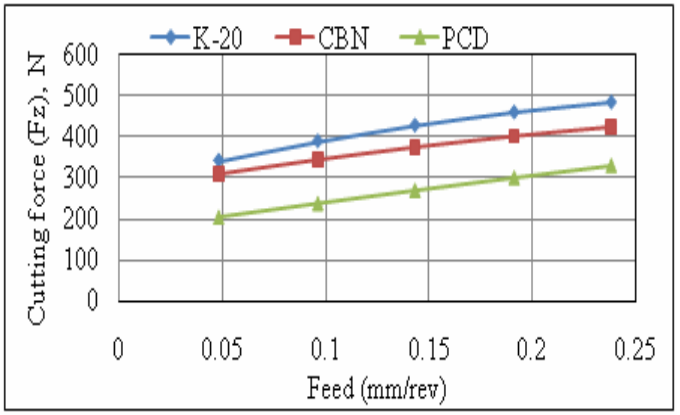

(a) Effect of cutting tool material on cutting force With varying feed for $30^{\circ}$ fiber orientaion angle GFRP compoiste.

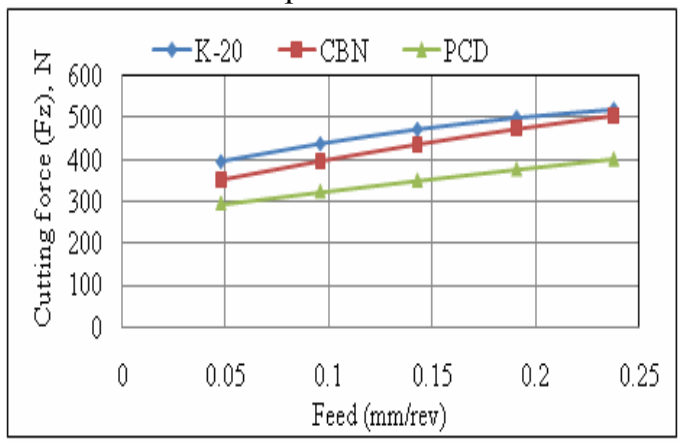

(c) Effect of cutting tool material on cutting force With varying feed for $60^{\circ}$ fiber orientaion angle GFRP compoiste.

Figure 12 (a-d). Effect of cutting tool material on cutting force with varying feed

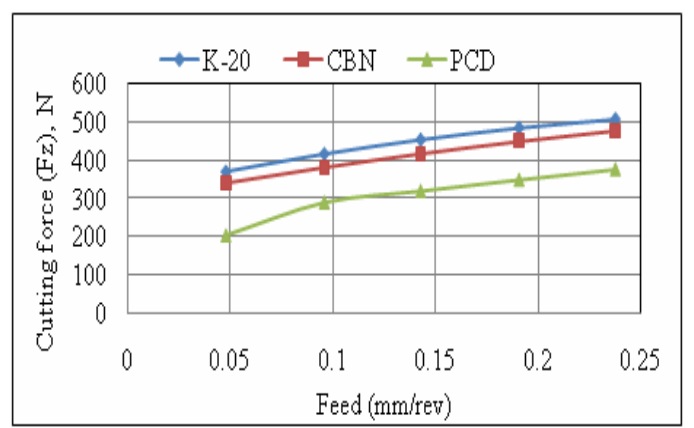

(b) Effect of cutting tool material on cutting force with varying feed for $45^{\circ}$ fiber orientation angle GFRP compoiste.

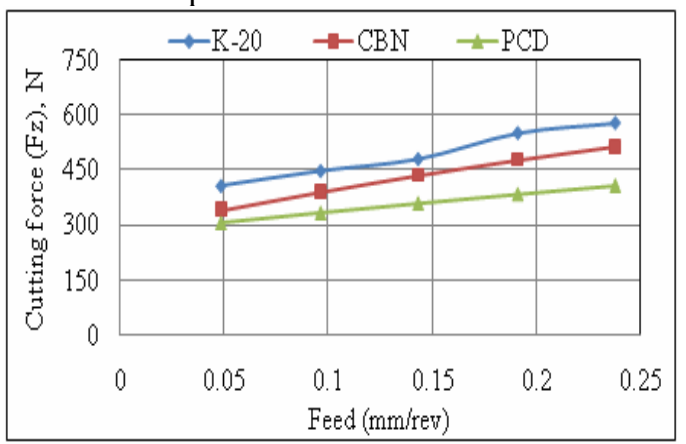

(d) Effect of cutting tool material on cutting force with varying feed for $75^{\circ}$ fiber orientation angle GFRP compoiste 


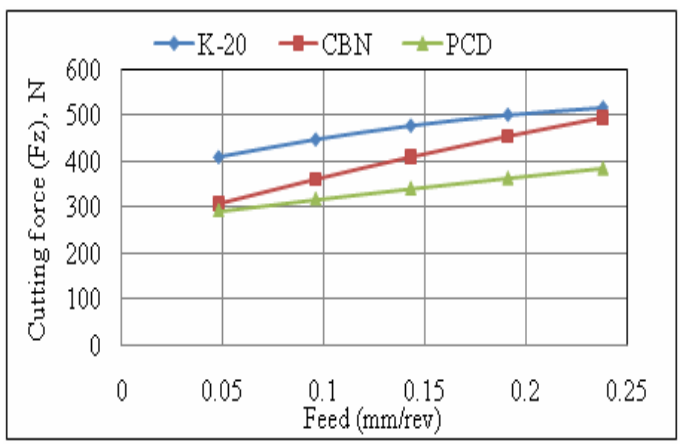

(e) Effect of cutting tool material on cutting force

with varying feed for $90^{\circ}$ fiber orientation angle

GFRP composite.

Figure 12 (e). Cont'd. Effect of cutting tool material on cutting force with varying feed

Figure 12 (a-e) illustrates the effect of effect of cutting tool material on cutting force with varying feed on GFRP composite materials of different fiber orientation angle ranges from $30^{\circ}$ to $90^{\circ}$. These graphs are drawn with the help of response surface model by keeping one variable in variation and keeping the other variable constant at the middle level. From the graphs, it is asserted that the increase in feed rate increases the cutting force for all GFRP composite materials of different fiber orientation angles. It is obvious that, with increase in feed rate, the contact area between work and tool increases. As a result, the material removal rate increases, which contribute to increase in cutting force. It can be seen from the graphs, lower cutting forces ranges from $202.72 \mathrm{~N}$ to $327.57 \mathrm{~N}$ are observed for $30^{\circ}$ fiber orientation angle GFRP composite materials with PCD cutting tool inserts used in this investigation compared to the higher fiber orientation angle GFRP composite materials. Figure 12(a-e) reveals that PCD tool insert performs better and yields lower cutting forces for all the GFRP composite materials used in the present investigation and this followed by $\mathrm{CBN}$ tool insert. Carbide (K-20) was not satisfactory compared to the tools used in this investigation.

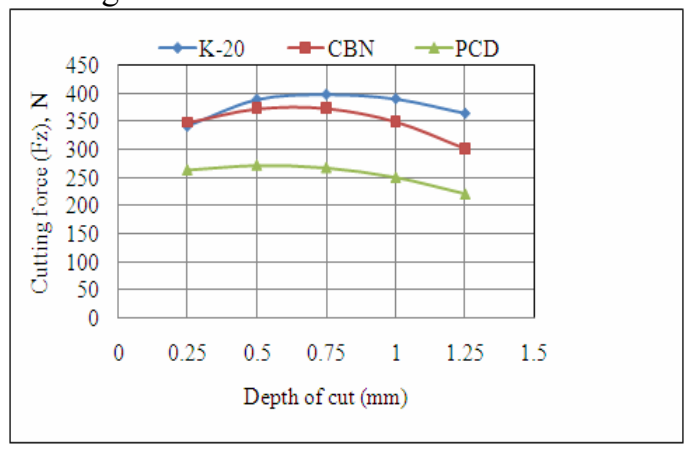

(a) Effect of cutting tool material on cutting force with varying depth of cut for $30^{\circ}$ fiber orientation angle GFRP composite.

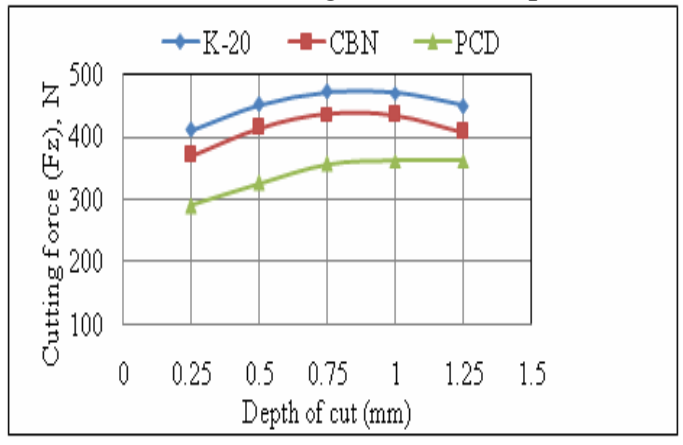

(c) Effect of cutting tool material on cutting force with varying depth of cut for $60^{\circ}$ fiber orientation angle GFRP composite.

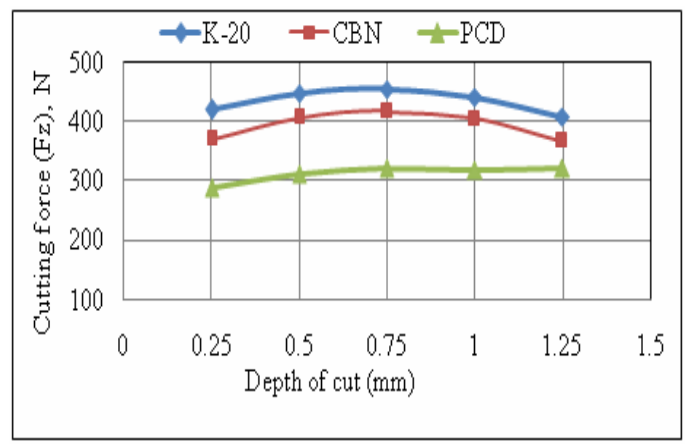

(b) Effect of cutting tool material on cutting force with varying depth of cut for $45^{\circ}$ fiber orientation angle GFRP composite.

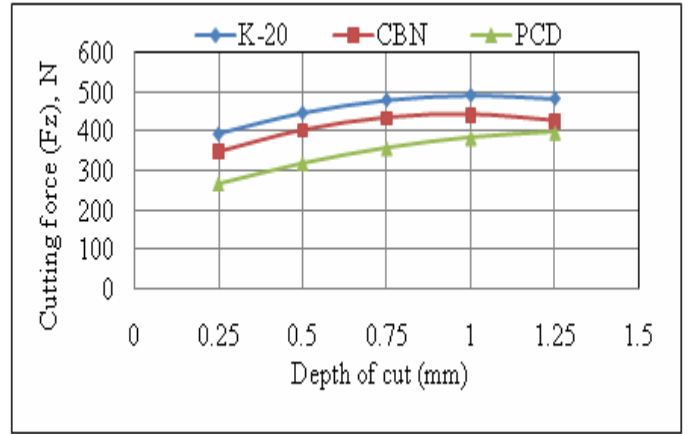

(d) Effect of cutting tool material on cutting force with varying depth of cut for $75^{\circ}$ fiber orientation angle GFRP composite

Figure 13 (a-d). Effect of cutting tool material on cutting force with varying depth of cut 


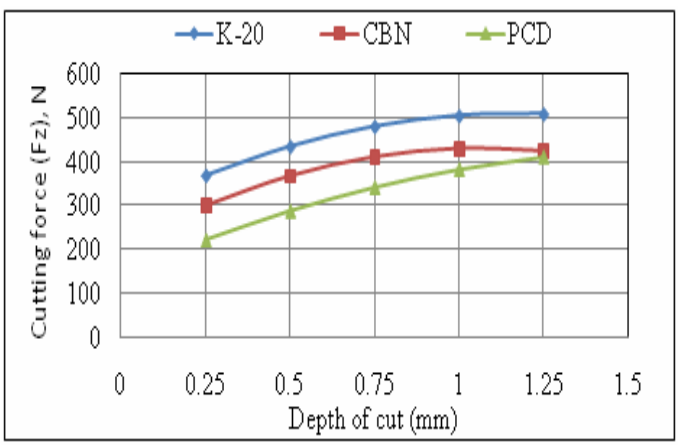

(e) Effect of cutting tool material on cutting force

with varying depth of cut for $90^{\circ}$ fiber orientation angle

GFRP composite.

Figure 13 (e). Cont'd. Effect of cutting tool material on cutting force with varying depth of cut

Figure 13 (a-e) illustrates the effect of cutting tool material on cutting force with varying depth of cut on GFRP composite materials of different fiber orientation angle ranges from $30^{\circ}$ to $90^{\circ}$. These graphs are drawn with the help of response surface model by keeping one variable in variation and keeping the other variable constant at the middle level. From the graphs, it is asserted that the increase in depth of cut to a value of $1.0 \mathrm{~mm}$ the cutting force increases and thereafter it decreases slightly for all GFRP composite materials of different fiber orientation angles. Normally in machining of GFRP composite materials depth of cut plays only a small role and this has been proved from this study. This finding has very close relationship with the findings of Sang Ook An et al.(1997). It can be seen from the graphs, lower cutting forces ranges from $220.64 \mathrm{~N}$ to $217.98 \mathrm{~N}$ are observed for $30^{\circ}$ fiber orientation angle GFRP composite material with PCD cutting tool inserts used in this investigation compared to the higher fiber orientation angle GFRP composite materials. Figure 13(a-e) reveals that PCD tool insert performs better and yields lower cutting forces for all the GFRP composite materials used in the present investigation and this followed by CBN tool insert. Because of high uniform hardness and wear rate of cutting edge is slower than that of cemented tungsten carbide tools. Reduced wear results in holding closer tolerances on work pieces. Carbide (K-20) was not satisfactory compared to the tools used in this investigation.

\section{Conclusion}

The present study deals with the investigation on some aspects of machinability such as surface roughness and cutting force during turning of GFRP composite materials for a range of fiber orientation angle $\left(30^{0}-90^{\circ}\right)$ with three different cutting tools viz., Carbide (K-20), CBN and PCD. Based on the experimental results, the following conclusions are drawn within the range of parameters selected.

- In machining of GFRP composites the surface roughness is highly influenced by feed followed by cutting speed and fiber orientation angle. Depth of cut has very little effect on surface roughness.

- Cutting forces are highly influenced by feed, followed by cutting speed and fiber orientation angle. Depth of cut has very little effect in machining GFRP composites.

- While machining GFRP composites, low cutting forces and better surface finish are observed while using PolyCrystalline Diamond (PCD) tool among other cutting tools used for the study. This is followed by cubic Boron Nitride (CBN) tool.

- Carbide (K-20) tool gave high surface roughness and high cutting forces hence, it is not at all desirable to use this tool for machining GFRP composites.

- While machining GFRP composites moderate cutting speed, low feed rate, moderate depth of cut and low fiber orientation angle are preferred.

- The developed models for surface roughness and cutting force using Response surface modeling are highly adequate as their $\mathrm{R}^{2}$ values are very close to 1 and hence all the models can be used for reliable prediction.

The future scope of work includes the following: (1) The number of machining parameters can be extended and hence, the data base can be improved by extensive experimentation; and (2) In this work, the experimental data has been modeled and analyzed by Response surface methodology (RSM). The same problem can be modeled and analyzed by an Adaptive Neuro-Fuzzy Inference System (ANFIS). 


\section{References}

Adam khan.M and A. Senthil kumar, 2011, Machinability of glass fiber reinforced plastic (GFRP) composites using aluminabased ceramic cutting tools International Journal of Manufacturing Process. Vol. 13, No.1, pp 67-73.

Bhatnagar, N., Ramakrishnan, N., Naik, N.K., and. Komandurai, R.,1995 On the machining of fiber Reinforced plastics (FRP) composite laminates", International Journal of Machine Tool Manufacturing., Vol.35, No.5, , pp 701-716

Davim JP, Mata F. 2004, Influence of cutting parameters on surface roughness using statistical analysis. Industrial Lubrication Tribology.Vol. 56 No. 5, pp 270-274.

Everstine, G.C., and. Rogers. T.G, 1971, A theory of machining of fiber reinforced materials, Journal of Composite. Materials, Vol. 5, pp 94-105.

Hull.D T.W.Clyne, 1996, An Introduction to composite materials, Second Edition, Cambridge University Press .

König.W Ch. Wulf, P. Graß and H. Willerscheid, 1985 A theory of machining of fiber reinforced plastics. CIRP AnnalsManufacturing Technology, Vol. 34, pp 537-548.

Montgomery DC 1991, Design and analysis of experiments. John Wiley and sons, NewYork,

Palani kunar.K, Karuna moothy. L and Kathikeyan. R ,2006, Assessment of factors influencing surface roughness on machining of Glass fiber reinforced polymer Composites, Materials \& Design Vol. 27, No.10, pp. 863-871.

Palanikumar, K. (2008) . Application of Taguchi and response surface methodology for surface roughness in machining glass fiber reinforced plastics by PCD Tooling, International Journal of Materials Processing Technology, Vol. 36, No. (1-2), pp. 19-27.

Palanikumar.K Studies on machining characteristics of glass fiber reinforced polymer composites, PhD Thesis, Anna University, Chennai, India. 2004.

Palanikumar, K., Karunamoothy, L., and Karthikeyan, R. 2004, Optimization of machining parameters for minimum surface roughness in turning of GFRP composites using design of experiment, Journal of. Material Science Technology, Vol. 20, No. 4, pp. 373-378.

Rahman M, Ramakrishnan S, Prakesh S, Tan DCG, 1999, Machinability study of carbon fiber reinforced composites, Journal of. Material Process Technology, Vol. 89-90, pp. 292-297.

Ramulu. M., Arola, D and Colligan. K., 1994, Preliminary investigation on the surface Integrity of fiber reinforced plastics, Engineering systems Design and Analysis, ASME., Vol. 64 No.2, pp. 93-101.

Sakuma.K and M.Seto 1983, Tool-wear in cutting glass-fiber-reinforced plastics the relation between fiber orientation and tool wear, Bulletein of the JSME, Vol. 26 , No. 218: , pp.1420-1427.

Sarma.PMMS, L. karunamoothy, K. Palanikumar, 2009, Surface roughness parameters evaluation in machining GFRP Composites by PCD tool using digital image processing, Journal of Reinforced Plastics and Composites, Vol. 28, pp. 1567-1585

Sang.-Ook An,, Lee, E.-S. and Noh, S.-L. A, 1997, Study on the cutting characteristics of glass fiber reinforced plastics with respect to tool materials and geometries, Journal of Materials Processing Technology, Vol. 68, pp. 60-67.

Takeyama, H. and Lijama, N. 1988, Machinability of glass fiber reinforced plastics and application of ultrasonic machining, Annal of CIRP, Vol. 37, No.1, pp. 93-96.

\section{Biographical notes}

Mr. Syed Altaf Hussain*, is an Associate Professor in the Department of Mechanical Engineering, RGM College of Engineering \& Technology, Nandyal518501,(A.P), India. He was graduated in Mechanical Engineering from Regional Engineering College, Waangal, A.P and Post graduated in the specialization of Machine Design from JNTU College of Engineering, Kakinada. At present he is pursuing Ph.D from JNT University,Anantapur, A.P, India. He has more than 13 years of experience in teaching. His current area of research includes, Machining of composite materials, Finite Element methods, Optimization, Simulation and Modeling.

Dr. V. Pandurangadu is a professor in the Department of Mechanical Engineering, JNT University-Anantapur, Anantapur-515002, Andhra Pradesh, India. He has more than 25 years of experience in teaching and research. His current area of research includes Alternative fuels for an I.C Engines, Combustion of fuels, Machining of composite materials.

Dr. K. Palanikumar is a principal, Sri Sairam Institute of Technology, Chennai-44, India. He obtained Ph.D degree in Mechanical Engineering from Anna university, Chennai, India. He has more than 17 years of experience in teaching and research. His current area of research includes Machining of composite materials, Modern manufacturing, Optimization, Simulation and Modeling.

Received May 2011

Accepted June 2011

Final acceptance in revised form June 2011 